\title{
Does Race Affect Outcomes in Total Joint Arthroplasty?
}

\author{
Carlos J. Lavernia MD, Jesus M. Villa MD
}

Published online: 5 August 2015

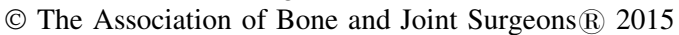

\begin{abstract}
Background Several studies suggest worse surgical outcomes among racial/ethnic minorities. There is a paucity of research on preoperative and postoperative pain, general health, and disease-specific measures in which race is the main subject of investigation; furthermore, the results are not conclusive.

Questions/purposes (1) Do black patients have more severe or more frequent preoperative pain, well-being, general health, and disease-specific scores when compared with white patients? (2) Are there differences between black patients and white patients after hip or knee arthroplasty on those same measures?
\end{abstract}

Each author certifies that he or she, or a member of his or her immediate family, has no funding or commercial associations (eg, consultancies, stock ownership, equity interest, patent/licensing arrangements, etc) that might pose a conflict of interest in connection with the submitted article.

All ICMJE Conflict of Interest Forms for authors and Clinical Orthopaedics and Related Research ${ }^{\circledR}$ editors and board members are on file with the publication and can be viewed on request.

Each author certifies that his or her institution approved the human protocol for this investigation, that all investigations were conducted in conformity with ethical principles of research, and that informed consent for participation in the study was obtained.

This work was performed at The Center for Advanced Orthopedics at Larkin Hospital, South Miami, FL, USA.

\section{J. M. Villa}

Arthritis Surgery Research Foundation, 7000 SW 62 Avenue, Suite 601, South Miami, FL 33143, USA

\section{J. Lavernia ( $₫)$, J. M. Villa}

The Center for Advanced Orthopedics at Larkin Hospital, 7000

SW 62 Avenue, Suite 600, South Miami, FL 33143, USA

e-mail: c@drlavernia.com
Methods In this retrospective study, we used an institutional arthroplasty registry to analyze data on 2010 primary arthroplasties (1446 knees and 564 hips) performed by one surgeon at a single institution. Cases from patients selfidentifying as black $(\mathrm{n}=105)$ and white $(\mathrm{n}=1905)$ were compared (controlling for confounders, including age and ethnicity) on the following preoperative and postoperative patient-oriented outcomes: pain intensity/frequency as measured by a visual analog scale (VAS), Quality of Well-Being (QWB-7), SF-36, and WOMAC scores. Ttests, chi square, and multivariate analysis of covariance were used. Alpha was set at 0.05 . Postoperative analysis was performed only on those cases that had a minimum followup of 1 year (mean, 3.5 years; range, 1-9 years). Of the 2010 arthroplasties, 37\% (39 of 105) of those cases performed in black patients and 64\% (1219 of 1905) of those performed in white patients were included in the final postoperative model (multivariate analysis of covariance).

Results Black patients had more severe preoperative pain intensity (VAS: $8 \pm 1.8$ versus $8 \pm 2.0$, mean difference $=$ 0.76 [95\% confidence interval $\{\mathrm{CI}\}, 0.34-1.1], \mathrm{p}<0.001$ ). Black patients also had worse well-being scores (QWB-7: $0.527 \pm 0.04$ versus $0.532 \pm 0.05$, mean difference $=$ -0.01 [CI, -0.02 to 0.00$], \mathrm{p}=0.037$ ). Postoperatively, pain intensity (VAS: $1 \pm 3.1$ versus $1 \pm 1.8$, mean difference $=0.8$ [CI, 0.19-1.4], $\mathrm{p}=0.010)$ and (QWB-7: 0.579 \pm 0.09 versus $0.607 \pm 0.11$, mean difference $=-0.049$ [CI, -0.08 to -0.01$], \mathrm{p}=0.008$ ) were different but without clinical significance.

Conclusions Black patients underwent surgery earlier in life and with different preoperative diagnoses when compared with white patients. Black patients had worse preoperative baseline pain, well-being, general health, and disease-specific scores as well as worse postoperative 
scores. However, these differences were very narrow and without clinical significance. Notwithstanding, the relations of race with outcomes remain complex. Further investigations to recognize disparities and minimize or address them are warranted.

Level of Evidence Level III, prognostic study.

\section{Introduction}

According to the US Census Bureau, people of any race may be of any ethnic origin [24]. Race and ethnicity (Hispanic or non-Hispanic) are separate and distinct concepts. US federal standards mandate that when collecting these data through self-identification for the US Census, two different questions must be used [23]. This concept is extremely important and should not be overlooked because any individual patient white or black may be Hispanic or non-Hispanic (ethnicity categories) [25].

Unfortunately, studies $[4,9,11]$ often fail to address race and ethnicity as separate entities and have compared Hispanics or Latinos with blacks, whites, or other races such as Native American or Alaska Native, Asian, Native Hawaiian, or other Pacific Islander [25]. The genetic background is linked to race, whereas its expression is influenced by cultural and/or environmental factors (like ethnicity). On top of that, few arthroplasty studies explicitly considered the impact of race on outcomes, and most of them are small $[1,4]$. According to a 2014 Journal of Bone and Joint Surgery editorial [10], in a search for Journal of Bone and Joint Surgery articles over the past 10 years, only three articles mentioned race in the title $[8,10,21]$ although many studies mentioned these in the text. Race was infrequently the main subject of study.

The sources of disparities when it comes to the study of race and its impact on musculoskeletal health are very complex [10]. Few publications have addressed the effects of race in hip and knee total arthroplasty outcomes [18]. Any study on race and arthroplasty outcomes should make a clear distinction between race and ethnicity and treat these as completely separate entities. In total hip and/or knee arthroplasty, outcomes such as pain, well-being, general health, and disease-specific scores may be affected by race.

We therefore asked: (1) Do black patients have more severe or more frequent pain (VAS) or lower well-being (Quality of Well-Being [QWB-7]), general health (SF-36) scores, and disease-specific scores (WOMAC) when compared with white patients? (2) Are there differences between black and white patients after hip or knee arthroplasty on those same measures?

\section{Materials and Methods}

Making use of our joint registry database, we retrospectively reviewed prospectively collected data on the records of 2142 primary THAs and TKAs (1665 patients) performed by the senior author (CJL) in a single institution from May 2003 to November 2012. All patients included in the study provided informed consent for this institutional review board-approved registry.

Revision cases, hemiarthroplasties, and preoperative joint infections were excluded from the study. We also excluded 128 primary arthroplasties performed in patients of unknown race and four primary procedures performed in three patients of Asian/Indian/Pakistani descent. As a result, 2010 cases (1446 knees and 564 hips; 1567 patients) were included in the study for statistical analysis. We assigned each case to one of two groups based on the selfidentification provided by patients: black group $(n=105)$ and white group $(n=1905)$. In the black group $44 \%$ (46 of 105 ) of cases were hips, whereas in the white group, this proportion was $27 \%$ (518 of 1905). Of the 2010 arthroplasties, 37\% (39 of 105) of those performed in black patients and 64\% (1219 of 1905) of those performed in white patients were available for followup at a minimum of 1 year (mean, 3.5 years; range, 1-9 years) and were included in the final postoperative model $(\mathrm{n}=1258)$ (multivariate analysis of covariance).

The same approaches to surgery, analgesia, and aftercare were used in all patients in this series, regardless of race. Patients were seen by the senior author (CJL) during the second and sixth postoperative weeks for clinical evaluation.

In our institution, patient-oriented outcomes are routinely collected in our joint registry database in a prospective fashion (2 weeks preoperatively and postoperatively at 3 months, 6 months, 1 year, and annually thereafter). For this investigation, data were prospectively collected but retrospectively reviewed. The two race groups (black and white) were compared in terms of baseline demographics, body mass index, comorbidities, preoperative diagnosis as well as preoperative and postoperative patient-oriented outcomes. Demographic data included age, gender (female/male), race (black/white), ethnicity (Hispanic/non-Hispanic), body mass index (BMI) $\left(\mathrm{kg} / \mathrm{m}^{2}\right)$ [17], American Society of Anesthesiologists (ASA) physical status classification system [2], Charlson Comorbidity Index (CCI) [7], and preoperative diagnosis. Patient-oriented outcomes included pain intensity and frequency as measured by a VAS (range, 0-10), the QWB-7 total score, which is a measure of quality of well-being [12], the SF-36, which is a measure of general health [3], and the WOMAC Osteoarthritis Index, which is a diseasespecific instrument commonly used for knees and hips [5]. 


\section{Statistical Analysis}

Independent t-, chi-square, and Fisher's exact tests were used to determine if there were differences between the black group and the white group or whether any specific variable was associated with a particular race (age, gender, ethnicity, BMI, ASA, CCI, preoperative diagnosis). Any substantial differences or associations among baseline demographic variables or preoperative diagnoses between races would necessitate those variables to be used as covariates in the preoperative and postoperative outcome statistical models. Using the general linear model in SPSS (Version 16.0; IBM Corp, Armonk, NY, USA), a multivariate analysis of covariance (MANCOVA) was used to assess for differences between the black group and the white group at the preoperative and postoperative points for all outcome measures (pain intensity/frequency VAS, QWB-7 total, SF-36, and WOMAC scores). Preoperatively, 1966 cases had complete data to be included in the MANCOVA model. Postoperatively, 1258 cases were included in the MANCOVA model. Analysis was made on available data. A p value $\leq 0.05$ was considered statistically significant.

Concerning baseline demographics, the mean age of the whole case-series was 70 years (range, 18-93 years). We found that black patients were younger when compared with white patients (mean, 63 years versus 70 years; $p<$ $0.001)$. There were fewer Hispanics $(36 \%)$ in the black group when compared with the proportion of Hispanics
(78\%) in the white group ( $\mathrm{p}<0.001)$. Preoperative diagnosis was also found different between the two groups $(\mathrm{p}<$ 0.001). In the black group, the proportion of cases with a preoperative diagnosis of avascular necrosis was almost five times the one of cases with this diagnosis within the white group. Likewise, the black group had twice the rate of cases with preoperative diagnosis of inflammatory arthritis when compared with the white group. The remaining baseline patient characteristics were not substantially different between the two groups (Table 1). In view of these group findings, preoperative and postoperative patient-oriented outcomes were compared between the black group and the white group controlling for age, ethnicity, and preoperative diagnosis.

\section{Results}

Association of Race and Outcomes Scores Before Surgery

We found that black patients had worse preoperative scores (after adjusting for age, ethnicity, and preoperative diagnosis) when compared with white patients (Table 2). Black patients had worse pain intensity (VAS: $8 \pm 1.8$ versus $8 \pm$ 2.0 , mean difference $=0.76[95 \%$ confidence interval $\{\mathrm{CI}\}$, $0.34-1.1], \mathrm{p}<0.001)$. Black patients also had worse wellbeing (QWB-7: $0.527 \pm 0.04$ versus $0.532 \pm 0.05$, mean difference $=-0.01$ [CI, -0.02 to 0.00$], \mathrm{p}=0.037$ ).

Table 1. Comparisons between the black group and the white group on baseline demographics, body mass index, comorbidities, and preoperative diagnosis

\begin{tabular}{|c|c|c|c|}
\hline Baseline patient characteristics & $\begin{array}{l}\text { Black group } \\
(\text { mean } \pm \mathrm{SD})\end{array}$ & $\begin{array}{l}\text { White group } \\
\text { (mean } \pm \mathrm{SD})\end{array}$ & $\mathrm{p}$ value \\
\hline Age (mean years) & $63 \pm 13.2$ & $70 \pm 9.9$ & $<0.001 *$ \\
\hline \multicolumn{4}{|l|}{ Gender ( $\%$ within race) } \\
\hline Female & 73 & 68 & \multirow[t]{2}{*}{0.3} \\
\hline Male & 27 & 32 & \\
\hline \multicolumn{4}{|l|}{ Ethnicity (\% within race) } \\
\hline Hispanic & 36 & 78 & \multirow[t]{2}{*}{$<0.001^{*}$} \\
\hline Non-Hispanic & 64 & 22 & \\
\hline Body mass index (mean kg/m²) & $31 \pm 5.4$ & $30 \pm 5.6$ & 0.4 \\
\hline Charlson Comorbidity Index (mean) & $1 \pm 1.4$ & $1 \pm 1.5$ & 0.3 \\
\hline ASA I ( $\%$ within ASA) & 13 & 87 & \multirow[t]{4}{*}{0.6} \\
\hline ASA II (\% within ASA) & 6 & 94 & \\
\hline ASA III ( $\%$ within ASA) & 5 & 95 & \\
\hline ASA IV (\% within ASA) & 11 & 89 & \\
\hline Osteoarthrosis primary (\% within race) & 74 & 90 & \multirow[t]{4}{*}{$<0.001 *$} \\
\hline Osteoarthrosis secondary (\% within race) & 4 & 4 & \\
\hline Inflammatory (\% within race) & 7 & 3 & \\
\hline Avascular necrosis (\% within race) & 15 & 3 & \\
\hline
\end{tabular}

* Statistically significant: alpha lower than 0.05; ASA = American Society of Anesthesiologists physical status classification. 
Table 2. Comparisons between the black group and the white group on preoperative patient-oriented outcomes (adjusting by age, ethnicity, and preoperative diagnosis)

\begin{tabular}{|c|c|c|c|c|}
\hline Dependent variable & $\begin{array}{l}\text { Black }(\mathrm{n}=101) \\
(\text { mean } \pm \text { SD) }\end{array}$ & $\begin{array}{l}\text { White }(\mathrm{n}=1865) \\
(\text { mean } \pm \text { SD })\end{array}$ & Mean difference $(95 \% \mathrm{CI})$ & $\mathrm{p}$ value \\
\hline Pain VAS intensity & $8 \pm 1.8$ & $8 \pm 2.0$ & $0.76(0.34-1.1)$ & $<0.001 *$ \\
\hline Pain VAS frequency & $8 \pm 2.2$ & $8 \pm 2.3$ & $0.41(-0.7$ to 0.8$)$ & 0.095 \\
\hline QWB-7 total & $0.527 \pm 0.04$ & $0.532 \pm 0.05$ & $-0.01(-0.02$ to 0.00$)$ & $0.037 *$ \\
\hline SF-36 physical functioning & $16 \pm 19$ & $17 \pm 18$ & $-4.57(-8.3$ to -0.7$)$ & $0.018 *$ \\
\hline SF-36 role physical & $7 \pm 24$ & $7 \pm 22$ & $0.23(-4.3$ to 4.8$)$ & 0.921 \\
\hline SF-36 bodily pain & $33 \pm 21$ & $36 \pm 20$ & $-4.21(-8.3$ to -0.04$)$ & $0.047 *$ \\
\hline SF-36 general health & $73 \pm 17$ & $75 \pm 18$ & $-2.81(-6.5$ to 0.8$)$ & 0.136 \\
\hline SF-36 vitality & $67 \pm 21$ & $66 \pm 21$ & $1.8(-2.6$ to 6.2$)$ & 0.426 \\
\hline SF-36 social functioning & $36 \pm 29$ & $43 \pm 30$ & $-9.67(-15.9$ to -3.3$)$ & $0.003 *$ \\
\hline SF-36 role emotional & $82 \pm 37$ & $75 \pm 41$ & $2.4(-6.2$ to 11.0$)$ & 0.585 \\
\hline SF-36 mental health & $77 \pm 17$ & $72 \pm 17$ & $3.2(-0.4$ to 6.8$)$ & 0.089 \\
\hline SF-36 Physical Component Summary & $24 \pm 7$ & $26 \pm 7$ & $-2.18(-3.7$ to -0.6$)$ & $0.005^{*}$ \\
\hline SF-36 Mental Component Summary & $57 \pm 10$ & $55 \pm 11$ & $0.91(-1.3$ to 3.2$)$ & 0.431 \\
\hline WOMAC function & $42 \pm 13$ & $38 \pm 12$ & $4.9(2.2-7.5)$ & $<0.001 *$ \\
\hline WOMAC pain & $11 \pm 3.7$ & $11 \pm 3.7$ & $0.79(0.02-1.5)$ & $0.044 *$ \\
\hline WOMAC stiffness & $4 \pm 2.2$ & $3 \pm 2.3$ & $0.6(0.1-1.09)$ & $0.015^{*}$ \\
\hline WOMAC total & $57 \pm 16$ & $52 \pm 16$ & $6.3(2.8-9.7)$ & $<0.001 *$ \\
\hline
\end{tabular}

$* \mathrm{p}$ value $<0.05$ (multivariate analysis); $\mathrm{CI}=$ confidence interval; VAS = visual analog scale (range, $0-10$ ); QWB-7 = Quality of Well-Being Index.

Association of Race and Outcomes Scores At 1-year Minimum Followup

Black patients had worse pain intensity as measured by the VAS $(1 \pm 3.1$ versus $1 \pm 1.8$, mean difference $=0.8[\mathrm{CI}$, $0.19-1.4], \mathrm{p}=0.010)$ as well as worse QWB-7 total $(0.579$ \pm 0.09 versus $0.607 \pm 0.11$, mean difference $=-0.049$ [CI, -0.08 to -0.01$], \mathrm{p}=0.008)$. The results concerning the SF-36 (role-physical, bodily pain, social functioning, mental health) and the WOMAC scores (function, pain, stiffness, total) are presented (Table 3).

\section{Other Relevant Findings}

It is important to note again that baseline age, ethnicity, and preoperative diagnoses were found to be different between the black group and the white group (Table 1). Mean age was $63 \pm 13.2$ years in the black group versus 70 \pm 9.9 years in the white group (mean difference $=-7.0$ $[\mathrm{CI},-9.7$ to $-4.4 ; \mathrm{p}<0.001)$. In the black group, $36 \%$ (37 of 103) of patients were Hispanics, whereas in the white group, this proportion was $78 \%$ (1481 of 1887). Odds ratio was 0.154 (95\% CI, 0.101-0.233; p < 0.001). These differences were considered in our preoperative and postoperative multivariate models.

\section{Discussion}

Although racial disparities in some THA or TKA outcomes have been described $[6,9,13,20,22]$, the real root causes of these differences are not fully understood [15]. Furthermore, previous investigations have confused the definitions of race and ethnicity (comparing apples to oranges) making it difficult to isolate or pinpoint the associations of race on the outcomes before and after total joint arthroplasty. Finally, the overall knowledge base on this topic itself is small [18]. We therefore asked: (1) Do black patients have more severe or more frequent pain (VAS) or lower well-being (QWB-7), general health (SF36) scores, and disease-specific scores (WOMAC), when compared with white patients? (2) Are there differences between black and white patients after hip or knee arthroplasty on those same measures?

Our results should be interpreted in light of several limitations. First, although the data were prospectively collected, this is a retrospective observational study, and consequently, some of the differences observed could be the result of variables that are unaccounted for. However, important patient characteristics known to influence outcomes such as baseline demographics, comorbidities, and preoperative diagnosis were included and analyzed. The higher proportion of avascular necrosis and inflammatory 
Table 3. Comparisons between the black group and the white group on postoperative patient-oriented outcomes (adjusting by age, ethnicity, and preoperative diagnosis)

\begin{tabular}{lccc}
\hline Dependent variable & $\begin{array}{c}\text { Black }(\mathrm{n}=39) \\
(\mathrm{mean} \pm \mathrm{SD})\end{array}$ & $\begin{array}{c}\text { White }(\mathrm{n}=1219) \\
(\mathrm{mean} \pm \mathrm{SD})\end{array}$ & Mean difference (95\% CI) \\
\hline Pain VAS intensity & $1 \pm 3.1$ & $1 \pm 1.8$ & $0.8(0.19-1.4)$ \\
Pain VAS frequency & $1 \pm 2.4$ & $1 \pm 1.8$ & $0.4(-0.17$ to 1.06$)$ \\
QWB-7 total & $0.579 \pm 0.09$ & $0.607 \pm 0.11$ & $-0.049(-0.08$ to -0.01$)$ \\
SF-36 physical functioning & $52 \pm 23$ & $49 \pm 19$ & $-3.0(-8.9$ to 2.9$)$ \\
SF-36 role physical & $67 \pm 45$ & $82 \pm 33$ & $-12.1(-22.8$ to -1.4$)$ \\
SF-36 bodily pain & $64 \pm 29$ & $69 \pm 19$ & $-6.5(-12.7$ to -0.2$)$ \\
SF-36 general health & $73 \pm 13$ & $72 \pm 9$ & $-1.5(-4.4$ to 1.3$)$ \\
SF-36 vitality & $70 \pm 17$ & $69 \pm 10$ & $-1.3(-4.7$ to 2.1$)$ \\
SF-36 social functioning & $72 \pm 22$ & $75 \pm 16$ & $-5.3(-10.5$ to -0.1$)$ \\
SF-36 role emotional & $90 \pm 27$ & $95 \pm 20$ & $-5.2(-12.08$ to 1.6$)$ \\
SF-36 mental health & $74 \pm 15$ & $74 \pm 9$ & $-3.0(-6.1$ to -0.07$)$ \\
SF-36 Physical Component Summary & $41 \pm 9$ & $42 \pm 7$ & $-2.2(-4.7$ to 0.2$)$ \\
SF-36 Mental Component Summary & $55 \pm 8$ & $55 \pm 5$ & $-1.2(-2.9$ to 0.4$)$ \\
WOMAC function & $7 \pm 12$ & $4 \pm 5$ & $2.3(0.3-4.2)$ \\
WOMAC pain & $2 \pm 3.7$ & $1 \pm 1.8$ & $0.042^{*}$ \\
WOMAC stiffness & $1 \pm 1.3$ & $0 \pm 0.6$ & 0.452 \\
WOMAC total & $9 \pm 17$ & $5 \pm 7$ & $0.045^{*}$ \\
\hline
\end{tabular}

* $\mathrm{p}$ value $<0.05$ (multivariate analysis); $\mathrm{CI}=$ confidence interval; VAS = visual analog scale; QWB-7 = Quality of Well-Being Index.

conditions in our black patients might also explain, at least partially, the pre- and postoperative differences found between our two groups. However, statistically significant baseline differences between the groups were included in the preoperative and postoperative statistical models (MANCOVA) comparing them. Second, our sample was limited to a practice with a predominantly Hispanic population and we found this factor to be an important confounder. However, making use of multivariate analysis, we controlled for it. In this way, we were able to isolate race from ethnicity (and other confounders), which differentiate our study from others. Third, this study was limited to determine the effects of only two races (black and white); consequently, the results could not be extrapolated to other races or minority groups [25]. Race was defined by self-report, and how patients self-identify is a complex question that may involve biological, cultural, and social elements (how many "white" parents does it take for someone to be, or to self-identify as, white? Presumably this varies widely in studies that define race by self-report.). It is also important to note that the biology of race is quite controversial, and it may be much less biologically driven than once thought. We do not know to what extent this might influence our results. However, we do not think that these limitations invalidate our results because the perception of patients is currently more recognized and considered even for reimbursement purposes and any attempt to obtain groups with "pure" races for this or any study would be unrealistic. Fourth, this investigation made use of a relatively small number of procedures $(n=2010)$ when compared with larger administrative databases. However, granular information is available for each patient and all procedures were performed by a single surgeon in a single institution and the data were collected prospectively and in a standardized fashion. Consequently, we think that the information our data provides is unique and different than those of the larger administrative databases. Fifth, our sample belongs to a single practice and our results might not be extrapolated to other practices. However, our hospital is a community hospital and our results, with caution, could be generalized to community practices. Sixth, we did not have the same proportion of cases available for followup for the black and the white groups and this circumstance represents another limitation. Finally, although there were statistically significant differences in outcomes between our two race groups, these differences were narrow and do not seem to be of clinical importance. Consequently, from the clinical standpoint, the current investigation is a no difference study.

Preoperatively, we found that black patients had more severe pain intensity as measured by the VAS and worse scores for overall well-being (QWB-7 total), worse general health (SF-36), and disease-specific scores (WOMAC) when compared with white patients, which might suggest more severe arthritis symptoms. However, these differences were narrow and clinically unimportant. Our results, 
particularly on preoperative pain, are in agreement with the ones reported by Mossey [16] who performed an extensive literature review focused on racial/ethnic minority disparities in pain management and showed that individuals from racial/ethnic minorities are at increased risk of serious or activity-limiting pain. Regarding preoperative functional status outcomes, the senior author showed in a smaller case-series [13] that black patients undergoing total joint arthroplasty had lower scores than white patients in most outcome measures. Before arthroplasty, fear in black patients was found at higher levels when compared with the levels found in white patients. This might partly explain why black patients underwent surgery with more pain at baseline, because this fear might have resulted in black patients waiting longer before deciding to have for the intervention.

Postoperatively, black patients reported more pain as measured by the VAS and worse overall quality of wellbeing (QWB-7), general health (SF-36), and diseasespecific scores (WOMAC) when compared with white patients at a followup of at least 1 year after surgery. Our results are in agreement with the ones of Kamath et al [11]. The authors found that gender and race affected functional knee scores and ROM. Black patients had longer delays to presentation to surgery and experienced worse postoperative Knee Society scores; black women in particular experienced decreased postoperative flexion and ROM, which the authors attributed to a longer delay to surgery presentation. Access to care remains a problem for black patients and other minorities. Singh et al [20] performed an 18-year analysis of national Medicare data and found little evidence of declines in racial disparities for joint arthroplasty use or outcomes. This is important because delay to surgery might also explain, at least partially, preand postoperative results.

Regarding baseline patient characteristics, black patients underwent surgery at a younger average age when compared with white patients. This might be a reflection of the higher rate of avascular necrosis and inflammatory conditions in this group because these diagnoses commonly affect young patients [14, 19]. Self-designated Hispanic ethnicity was more frequently among white patients. We think that this finding is not surprising; rather, it reflects the characteristics of our population in Miami (a high proportion of white patients with origins in the Iberian Peninsula). In addition, in some Hispanic communities, darker color is associated with lower status. This factor was accounted for in our statistical analysis. As noted, black patients were more likely to have avascular necrosis and inflammatory conditions and a lower rate of primary osteoarthrosis.

Black patients underwent surgery early in life and with different preoperative diagnoses when compared with white patients. Black patients had statistically significant worse preoperative and postoperative outcomes. However, these differences were very narrow and without clinical significance. We have demonstrated that similar clinical outcomes can be achieved in black and white patients. Notwithstanding, the relations of race with outcomes remain complex. Further investigations attempting to fully understand the effects of race on total joint arthroplasty outcomes and other measures are warranted to recognize disparities and to minimize or address them.

Acknowledgments We thank Mark D. Rossi PhD (Florida International University) for his statistical and technical support.

\section{References}

1. Allen Butler R, Rosenzweig S, Myers L, Barrack RL. The Frank Stinchfield Award: the impact of socioeconomic factors on outcome after THA: a prospective, randomized study. Clin Orthop Relat Res. 2011;469:339-347.

2. American Society of Anesthesiologists ASA physical status classification system. 2015. Available at: https://www.asahq.org/ resources/clinical-information/asa-physical-status-classificationsystem. Accessed March 30, 2015.

3. Arocho R, McMillan CA, Sutton-Wallace P. Construct validation of the USA-Spanish version of the SF-36 health survey in a Cuban-American population with benign prostatic hyperplasia. Qual Life Res. 1998;7:121-126.

4. Barrack RL, Ruh EL, Chen J, Lombardi AV Jr, Berend KR, Parvizi J, Della Valle CJ, Hamilton WG, Nunley RM. Impact of socioeconomic factors on outcome of total knee arthroplasty. Clin Orthop Relat Res. 2014;472:86-97.

5. Bellamy N, Buchanan WW, Goldsmith $\mathrm{CH}$, Campbell J, Stitt LW. Validation study of WOMAC: a health status instrument for measuring clinically important patient relevant outcomes to antirheumatic drug therapy in patients with osteoarthritis of the hip or knee. J Rheumatol. 1988;15:1833-1840.

6. Cai X, Cram P, Vaughan-Sarrazin M. Are African American patients more likely to receive a total knee arthroplasty in a lowquality hospital? Clin Orthop Relat Res. 2012;470:1185-1193.

7. Charlson ME, Pompei P, Ales KL, MacKenzie CR. A new method of classifying prognostic comorbidity in longitudinal studies: development and validation. J Chronic Dis. 1987;40:373-383.

8. Day CS, Lage DE, Ahn CS. Diversity based on race, ethnicity, and sex between academic orthopaedic surgery and other specialties: a comparative study. J Bone Joint Surg Am. 2010;92: 2328-2335.

9. Ibrahim SA, Stone RA, Han X, Cohen P, Fine MJ, Henderson WG, Khuri SF, Kwoh CK. Racial/ethnic differences in surgical outcomes in veterans following knee or hip arthroplasty. Arthritis Rheum. 2005;52:3143-3151.

10. James MA, Tolo VT. Studying and reporting sex and race differences in musculoskeletal health. J Bone Joint Surg Am. 2014;96:89.

11. Kamath AF, Horneff JG, Gaffney V, Israelite CL, Nelson CL. Ethnic and gender differences in the functional disparities after primary total knee arthroplasty. Clin Orthop Relat Res. 2010;468:3355-3361.

12. Kaplan RM, Anderson JP, Wu AW, Mathews WC, Kozin F, Orenstein D. The Quality of Well-being Scale. Applications in AIDS, cystic fibrosis, and arthritis. Med Care. 1989;27:S27-43. 
13. Lavernia CJ, Alcerro JC, Rossi MD. Fear in arthroplasty surgery: the role of race. Clin Orthop Relat Res. 2010;468:547-554.

14. Lavernia CJ, Sierra RJ, Grieco FR. Osteonecrosis of the femoral head. J Am Acad Orthop Surg. 1999;7:250-261.

15. Morgan RC Jr, Slover J. Breakout session: ethnic and racial disparities in joint arthroplasty. Clin Orthop Relat Res. 2011;469: 1886-1890.

16. Mossey JM. Defining racial and ethnic disparities in pain management. Clin Orthop Relat Res. 2011;469:1859-1870.

17. National Institutes of Health. Calculate your body mass index. 2015. Available at: http://www.nhlbi.nih.gov/health/educational/ lose_wt/BMI/bmicalc.htm. Accessed April 2, 2015.

18. Nwachukwu BU, Kenny AD, Losina E, Chibnik LB, Katz JN. Complications for racial and ethnic minority groups after total hip and knee replacement: a review of the literature. J Bone Joint Surg Am. 2010;92:338-345.

19. Pakos EE, Paschos NK, Xenakis TA. Long term outcomes of total hip arthroplasty in young patients under 30. Arch Bone $J t$ Surg. 2014;2:157-162.
20. Singh JA, Lu X, Rosenthal GE, Ibrahim S, Cram P. Racial disparities in knee and hip total joint arthroplasty: an 18-year analysis of national Medicare data. Ann Rheum Dis. 2014;73: 2107-2115.

21. Skinner J, Zhou W, Weinstein J. The influence of income and race on total knee arthroplasty in the United States. J Bone Joint Surg Am. 2006;88:2159-2166.

22. Smedley BD SA, Nelson AR, eds. Unequal treatment: confronting racial and ethnic disparities in healthcare. 2003. Available at: http:// www.nap.edu/catalog/12875/unequal-treatment-confronting-racialand-ethnic-disparities-in-health-care. Accessed April 1, 2015.

23. US Census Bureau. The Hispanic population: 2010. 2015. Available at: http://www.census.gov/prod/cen2010/briefs/c2010br-04.pdf. Accessed April 1, 2015.

24. US Census Bureau. Race. 2015. Available at: http://census.gov/ topics/population/race.html. Accessed April 1, 2015.

25. US Census Bureau. Race about. 2015. Available at: http://www. census.gov/topics/population/race/about.html. Accessed April 2, 2015. 